\title{
Outcomes of a Digitally Delivered Low-Carbohydrate Type 2 Diabetes Self-Management Program: 1-Year Results of a Single-Arm Longitudinal Study
}

Laura R Saslow ${ }^{1}$, PhD; Charlotte Summers ${ }^{2}$; James E Aikens ${ }^{3}$, PhD; David J Unwin ${ }^{4}$, FRCGP

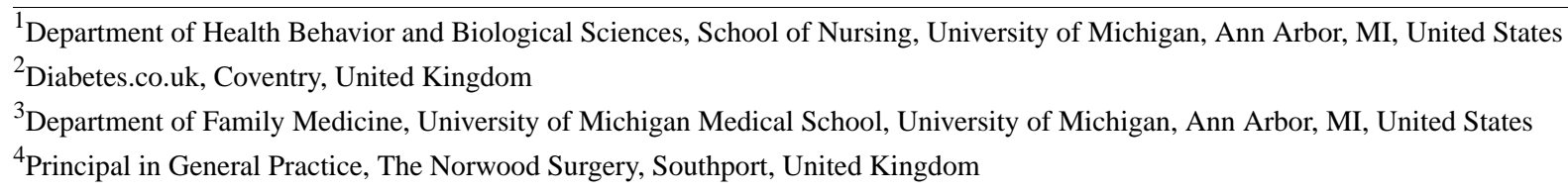

Corresponding Author:

Laura R Saslow, PhD

Department of Health Behavior and Biological Sciences

School of Nursing

University of Michigan

Room 2178 400NIB

Ann Arbor, MI, 48109-5482

United States

Phone: 1 (734) 7647836

Email: saslowl@umich.edu

\section{Abstract}

Background: Type 2 diabetes mellitus has serious health consequences, including blindness, amputation, stroke, and dementia, and its annual global costs are more than US $\$ 800$ billion. Although typically considered a progressive, nonreversible disease, some researchers and clinicians now argue that type 2 diabetes may be effectively treated with a carbohydrate-reduced diet.

Objective: Our objective was to evaluate the 1-year outcomes of the digitally delivered Low-Carb Program, a nutritionally focused, 10-session educational intervention for glycemic control and weight loss for adults with type 2 diabetes. The program reinforces carbohydrate restriction using behavioral techniques including goal setting, peer support, and behavioral self-monitoring.

Methods: The study used a quasi-experimental research design comprised of an open-label, single-arm, pre-post intervention using a sample of convenience. From adults with type 2 diabetes who had joined the program and had a complete baseline dataset, we randomly selected participants to be followed for 1 year ( $N=1000$; mean age 56.1, SD 15.7 years; 59.30\% (593/1000) women; mean glycated hemoglobin $\mathrm{A}_{1 \mathrm{c}}\left(\mathrm{HbA}_{1 \mathrm{c}}\right)$ 7.8\%, SD 2.1\%; mean body weight $89.6 \mathrm{~kg}$, SD 23.1 kg; taking mean 1.2, SD 1.01 diabetes medications).

Results: Of the 1000 study participants, 708 (70.80\%) individuals reported outcomes at 12 months, 672 (67.20\%) completed at least $40 \%$ of the lessons, and $528(52.80 \%)$ completed all lessons of the program. Of the 743 participants with a starting $\mathrm{HbA}_{1 \mathrm{c}}$ at or above the type 2 diabetes threshold of $6.5 \%, 195(26.2 \%)$ reduced their $\mathrm{HbA}_{1 \mathrm{c}}$ to below the threshold while taking no glucose-lowering medications or just metformin. Of the participants who were taking at least one hypoglycemic medication at baseline, $40.4 \%$ (289/714) reduced one or more of these medications. Almost half (46.40\%, 464/1000) of all participants lost at least $5 \%$ of their body weight. Overall, glycemic control and weight loss improved, especially for participants who completed all 10 modules of the program. For example, participants with elevated baseline $\mathrm{HbA}_{1 \mathrm{c}}(\geq 7.5 \%)$ who engaged with all 10 weekly modules reduced their $\mathrm{HbA}_{1 \mathrm{c}}$ from $9.2 \%$ to $7.1 \%(P<.001)$ and lost an average of $6.9 \%$ of their body weight $(P<.001)$.

Conclusions: Especially for participants who fully engage, an online program that teaches a carbohydrate-reduced diet to adults with type 2 diabetes can be effective for glycemic control, weight loss, and reducing hypoglycemic medications.

(JMIR Diabetes 2018;3(3):e12) doi: 10.2196/diabetes.9333

\section{KEYWORDS}

eHealth; diet; weight loss; type 2 diabetes mellitus 


\section{Introduction}

Type 2 diabetes mellitus is prevalent, costly, and a potentially progressive disease with serious health consequences including blindness, amputation, stroke, dementia, and premature death [1]. Globally, one in 11 people, or 422 million adults, have diabetes (with most of those cases being type 2 diabetes) [2]. It is the most expensive disease in the United States [3], and its annual global costs are more than US $\$ 800$ billion [4]. In community settings, type 2 diabetes is rarely reversed. For example, a study that followed more than 100,000 patients with type 2 diabetes over 7 years found that less than $1 \%$ of patients experienced complete remission [5].

Although typically considered a progressive, nonreversible disease, some researchers and clinicians now argue that type 2 diabetes may be effectively treated with a carbohydrate-reduced diet, which could improve type 2 diabetes management and potentially even lead to remission [6]. Indeed, previous research with carbohydrate-reduced diets for type 2 diabetes do show improved outcomes (eg, glycemic control, weight loss, and reductions in the use of hypoglycemic medications) for both very low-carbohydrate diets (approximately $20 \%$ or fewer of total dietary calories derived from carbohydrates) [7-9] or lower carbohydrate diets (approximately $40 \%$ or fewer of total dietary calories derived from carbohydrates) $[10,11]$.

Although dietary interventions have historically been in-person, online programs can be just as effective for some participants, as suggested by research that has examined diet and lifestyle interventions in adults with prediabetes [12]. Therefore, it is perhaps not surprising that the beneficial results of carbohydrate-reduced diets for people with type 2 diabetes (glycemic control, weight loss, and reductions in the use of hypoglycemic medications) have been replicated using online programs [13,14]. Notably, both previous trials of a very low-carbohydrate diet online for adults with type 2 diabetes included the use of a coach. However, previous research on weight loss (including some people with type 2 diabetes), have shown some success with a completely automated online weight loss program, with approximately $50 \%$ of participants losing at least $5 \%$ of their body weight by 6 months $[15,16]$.

In this naturalistic pilot study, our objective was to evaluate the 1-year outcomes of the Low-Carb Program, a digitally delivered, nutrition-focused, structured lifestyle intervention with 10 weekly sessions for glycemic control, hypoglycemic medication use, and weight loss for adults with type 2 diabetes. We hypothesized that this program would lead to improvements compared to baseline: better glycemic control (as measured by glycated hemoglobin $\mathrm{A}_{1 \mathrm{c}}$ or $\mathrm{Hb}_{1 \mathrm{c}}$ ), weight loss, and reductions in hypoglycemic medication use. Our goal was to explore whether the program might be an effective option for increasing access to diabetes management solutions and help halt the prevalent, costly, and dangerous type 2 diabetes epidemic.

\section{Methods}

\section{Research Design}

We used a quasi-experimental research design comprised of a single-arm pre-post intervention. Participants were not paid for their participation, but because the program was free, they took part in the program at no cost. The University of Michigan Institutional Review Board (IRB) ruled that analyses of these previously collected and de-identified data were not subject to IRB regulation.

\section{Participants}

We recruited participants to this trial in three phases. The first phase recruited a sample of convenience following the launch of the Low-Carb Program (November 14, 2015-November 14, 2016), whereby 105,950 adults with type 2 diabetes between the ages of 18 and 99 years signed up to participate in the program. Participants could live anywhere in the world. To have a broad applicability to a nonclinical trial setting, the only de facto exclusion criterion was the inability to understand English. Second, upon sign-up, the program prompted individuals to complete an initial baseline survey; 19,646 of 105,950 (18.54\%) did so. Of those, 7809 people had complete baseline datasets including weight, a recent $\mathrm{HbA}_{1 \mathrm{c}}$ result (taken within 4 months), and medication use. Third, we used GraphPad Random Generator Software to randomly select a subset of 1000 participants to be followed for 12 months, thus enabling us to select participants for no other reason than that they were randomly selected by the software. Therefore, we did not include all the 7809 patients to follow over a year, but instead followed a random subsample of 1000 (see Figure 1).

\section{The Low-Carb Program}

The Low-Carb Program is a completely automated, structured 10 -week health intervention for adults with type 2 diabetes. Participants are given access to nutrition-focused modules, with a new module available each week over the course of 10 weeks. The modules are designed to help participants gradually reduce their total carbohydrate intake to less than 130 grams per day to meet their self-selected goals. The program encourages participants to make behavior changes based on "action points" or behavior change goals at the end of each module. These goals are supported with resources that are available to download, including information sheets, recipes, and suggested food substitution ideas. The Low-Carb Program online platform also includes digital tools for submitting self-monitoring data on a number of different variables including blood glucose levels, blood pressure, mood, sleep, food intake, and body weight. Weekly automated feedback is provided to users based on their use of the program through email notifications, and participants are notified when the next week's module has been opened. Lessons are taught through videos, written content, or podcasts of varying lengths (approximately 3 to 12 minutes long). 
Figure 1. Study participant flowchart for the study.

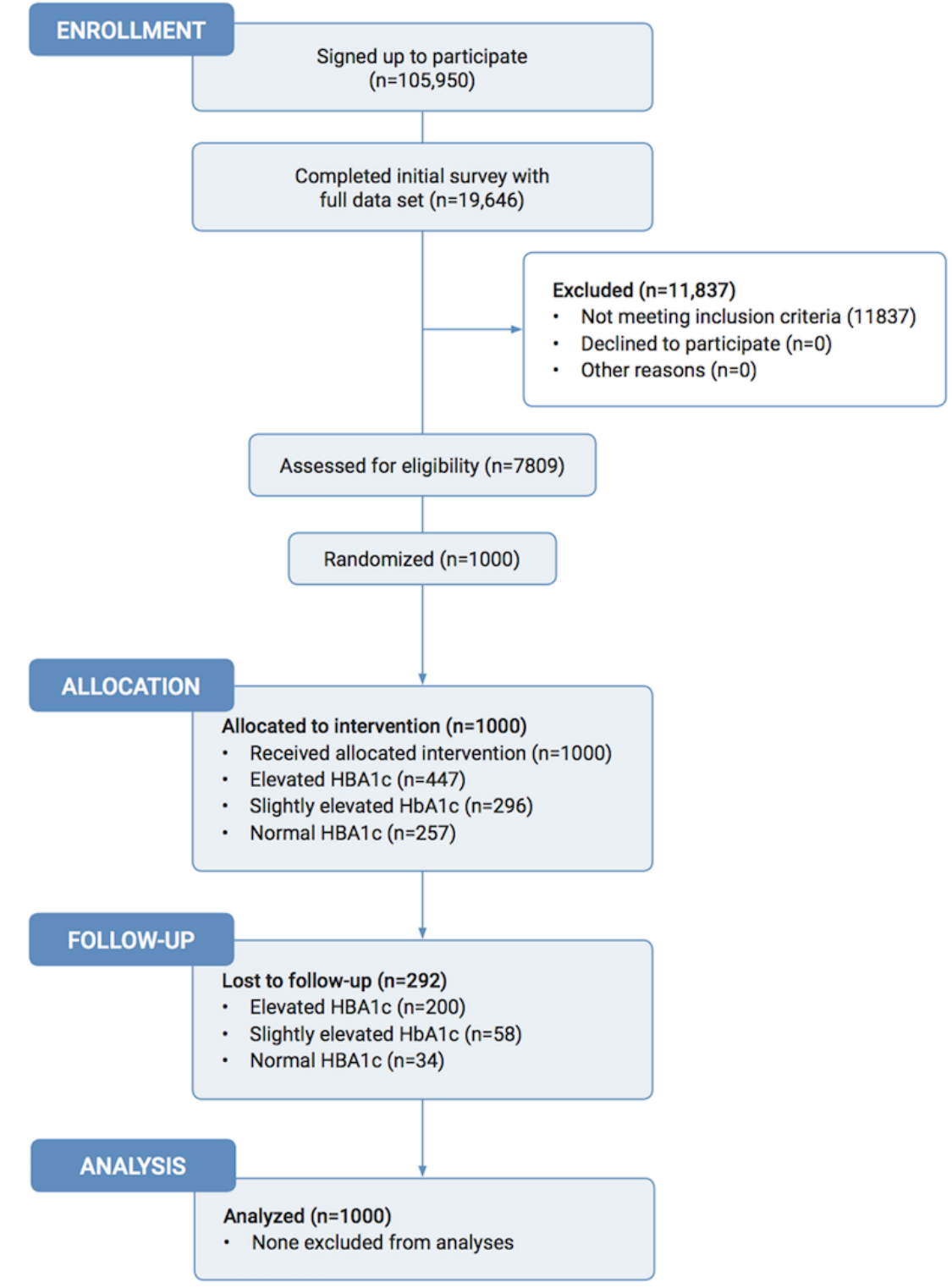

The first 2 weeks of the program contain an explanation of the physiology of type 2 diabetes and the role of diet, including a description of how a low-carbohydrate diet can help manage postprandial blood glucose levels and weight. The subsequent week's modules explore strategies to reduce dietary sources of sugar, in particular, high-starch foods, such as bread, pasta, and rice. Participants are encouraged to make portion control and carbohydrate restriction decisions based on visual plate representations. In place of carbohydrate-rich foods, an increased intake of green vegetables, low-glycemic index fruits (eg, blueberries, strawberries, and raspberries) and fats (eg, from olive oil, butter, eggs, nuts, and full-fat dairy) are advocated. The program stresses the importance of regular contact with the participants' health care providers for adjustments in medications in weeks 1,2 , and 10 . After the 10 weeks of modules have been opened, participants continue to have access to the education content as well as the ability to continue to track their health (glycemic control, weight) and access support from the discussion board. See Table 1 for a list of the weekly topics.

Much of the content of the Low-Carb Program is based on an in-person, nurse- and physician-led, low-carbohydrate training program conducted in a primary health care setting [17]. For example, the dietary recommendations reflect an understanding of the glycemic index, a relative ranking of carbohydrates in foods according to how they affect blood glucose levels. A meal of pure glucose (the index food) has a score of 100, boiled potatoes are scored at 96, cornflakes at 93, and brown bread at 74 , all of which are higher than table sugar at 63 [18]. This kind of information helps participants understand that both sugary and starchy foods increase blood glucose, and it also explains why the UK's National Institute for Health and Care Excellence advises physicians to "encourage high-fiber, low-glycemic index sources of carbohydrate in the diet" for type 2 diabetes [19]. Based on this, the program suggests a reduction in all sugary foods and replacing starchy foods, such as potato or rice, with green leafy vegetables, healthy fats, and some protein. 
Table 1. Weekly topics of the Low-Carb Program.

\begin{tabular}{|c|c|c|}
\hline Week & Title & Objective \\
\hline 1 & Welcome to the Low-Carb Program & $\begin{array}{l}\text { Safety notes and alerts to medications that require health team's assistance; initiate } \\
\text { conversation with health care providers prior to making any dietary adaptations; } \\
\text { benefits of a reduced carbohydrate diet for people with type } 2 \text { diabetes }\end{array}$ \\
\hline 2 & Type 2 diabetes and diet & $\begin{array}{l}\text { Factors that affect blood glucose levels; encouragement to engage with their health } \\
\text { care providers }\end{array}$ \\
\hline 3 & Controlling portion sizes & Visual methods of interpreting portion size \\
\hline 4 & Processed versus unprocessed foods & Identifying and eliminating refined and processed food \\
\hline 5 & Healthy and unhealthy fats & Discussion of fat types and making appropriate choices depending on goals \\
\hline 6 & Vegetables & The carbohydrate content of vegetables; cooking methods \\
\hline 7 & Sugar and starch & Reviewing the amount of sugar and starch in fruit and vegetables \\
\hline 8 & Snacks, desserts, and drinks & Examining low-carb snack, dessert, and drink options \\
\hline 9 & Alcohol, eating away from home & Alcohol; options for eating away from home \\
\hline 10 & Practical ways of reducing carbohydrate intake further & $\begin{array}{l}\text { Practical tips for reducing carbohydrate intake further; safety information-high- } \\
\text { lighting medications that require assistance from their physicians and how to involve } \\
\text { their physician and wider health care team }\end{array}$ \\
\hline
\end{tabular}

The content and strategies used in the program build off prior research and theory. For example, evidence suggests that goal setting can act as an effective behavior change strategy used to improve adherence to lifestyle intervention programs in obesity management programs [20]. Therefore, the program encourages participants to select a goal at the beginning of the program (eg, to lose weight, reduce medication dependency, or make healthier choices for their whole family). Participants are also prompted to consider how their health would benefit from attaining their goal. Throughout the program, participants are periodically prompted to consider how close they are to attaining their goal.

The program further reinforces behavior change through integrated tracking whereby program users are encouraged to track their health data including mood, food intake, blood glucose levels, weight, sleep, and $\mathrm{HbA}_{1 \mathrm{c}}$. According to the Control Theory of behavior change, monitoring goal progress - that is, evaluating one's ongoing performance relative to the standard - and responding accordingly is critical to goal attainment [21]. Recent findings suggest that program interventions that elevate the frequency of progress monitoring are likely to induce behavior change [22].

In addition, prior studies demonstrate that peer support may improve blood glucose control [23,24], peer-based support may be as effective for weight loss as coach-based support [25], and that online discussion boards can be supportive for weight loss [26]. Therefore, the program encourages social support by matching new participants of the program to a "buddy," a previous graduate of the program, based on similar demographics including age, gender, and their self-selected goal. Participants are encouraged to interact with that buddy and peers on the program's moderated online discussion board.

\section{Measures}

At baseline, an online survey asked participants to report on their type of diabetes, year of diagnosis, their most recent $\mathrm{HbA}_{1 \mathrm{c}}$ test result and date, current medications (medication name, dose, and regimen), age, gender, socioeconomic status (based on household income), and presence of comorbid chronic illnesses. At 12 months, participants were again asked to report on their current $\mathrm{HbA}_{1 \mathrm{c}}$, weight, and medications.

\section{Statistical Analyses}

Analyses were performed using the SPSS version 21.0 (SPSS Inc, Chicago, IL, USA). We examined the difference in characteristics from baseline to 12-month follow-up using paired $t$ tests. The primary outcome was change in $\mathrm{HbA}_{1 \mathrm{c}}$ and body weight $(\mathrm{kg}$, percent of initial body weight). The secondary outcome was change in need for diabetes medication. We stratified our cohort into three groups according to baseline glycemic control as defined by baseline $\mathrm{HbA}_{1 \mathrm{c}}$ : (1) elevated baseline $\mathrm{HbA}_{1 \mathrm{c}}$ greater than or equal to $7.5 \%$, (2) slightly elevated baseline $\mathrm{HbA}_{1 \mathrm{c}} 6.5 \%$ to $7.4 \%$, or (3) normal baseline $\mathrm{HbA}_{1 \mathrm{c}}$ less than $6.5 \%$. Outcomes were also analyzed within strata based on participant's Low-Carb Program completion (ie, completers: engaged with all 10 of the Low-Carb Program weekly modules; $\mathrm{n}=528$ ), partial completers (engaged with 4-9 modules; $n=144$ ), or noncompleters (engaged with $\leq 3$ modules; $\mathrm{n}=328$ ).

Some of our results took into account the entire sample, regardless of follow-up information or lesson completion. For participants who did not report their outcomes at 12 months, we followed the highly conservative approach of assuming that they did not improve at all (last observation carried forward), by imputing their baseline values as their outcome values. For example, participants who did not comply with reporting a 12-month outcome were treated as having no change in the outcome variable, and thus were not counted as having any $\mathrm{HbA}_{1 \mathrm{c}}$ or weight improvement.

\section{Results}

\section{Participant Characteristics at Baseline}

At baseline, mean $\mathrm{HbA}_{1 \mathrm{c}}$ was $7.8 \%$ (SD 2.1\%), mean weight was $89.6 \mathrm{~kg}$ (SD 23.1), and mean age was 56.1 years (SD 15.7) 
years. More than half of participants were female $(59.3 \%$, 593/1000), 90.4\% (904/1000) were white, all were from the United Kingdom, and more than one-third had comorbid hypertension $(39.7 \%, 397 / 1000)$ or hypercholesterolemia $(35.0 \%, 350 / 1000)$. At baseline, participants were taking a mean of 1.21 (SD 1.01) hypoglycemic medications. See Table 2 for details.

\section{Retention}

Of the 1000 baseline participants, 708 (70.80\%) reported outcomes at 12 months, $528(52.80 \%)$ completed all lessons, and $672(67.20 \%)$ completed at least $40 \%$ of the lessons. For the remaining 292 people lost to follow-up, the last recorded data point was carried forward. Of 447 people with elevated $\mathrm{HbA}_{1 \mathrm{c}}(\geq 7.5 \%)$ at baseline, $247(55.3 \%)$ reported outcomes at 12 months and $191(42.7 \%)$ completed all lessons. Of 296 people with slightly elevated $\mathrm{HbA}_{1 \mathrm{c}}(6.5 \%-7.5 \%)$ at baseline, $238(80.4 \%)$ had outcomes at 12 months and $182(61.4 \%)$ completed all lessons. Of 257 people with a normal baseline $\mathrm{HbA}_{1 \mathrm{c}}$ level $\left(\mathrm{HbA}_{1 \mathrm{c}}<6.5 \%\right)$ who began the study, $223(86.8 \%)$ had outcomes at 12 months and 155 (60.3\%) completed all lessons (see Figure 1 for the participant flowchart of the study).

Table 2. Participant characteristics at baseline.

\begin{tabular}{|c|c|c|c|c|}
\hline \multirow[t]{2}{*}{ Characteristic } & \multirow[t]{2}{*}{ Pooled $(\mathrm{N}=1000)$} & \multicolumn{3}{|c|}{ 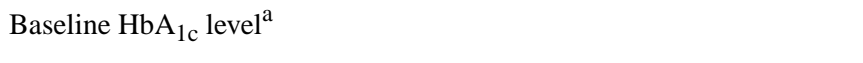 } \\
\hline & & Elevated $(n=447)$ & Slightly elevated $(\mathrm{n}=296)$ & Normal $(n=257)$ \\
\hline Age (years), mean (SD) & $56.1(15.7)$ & $54.8(14.6)$ & $56.7(16.9)$ & $57.9(15.8)$ \\
\hline $\mathrm{HbA}_{1 \mathrm{c}}(\%)$, mean $(\mathrm{SD})$ & $7.8(2.1)$ & $9.6(1.8)$ & $6.90(0.3)$ & $5.68(0.7)$ \\
\hline Weight $(\mathrm{kg})$, mean (SD) & $89.6(23.1)$ & $92.9(24.0)$ & $88.2(22.4)$ & $85.7(21.8)$ \\
\hline \multicolumn{5}{|l|}{ Gender, n (\%) } \\
\hline Male & $401(40.1)$ & $175(39.1)$ & $124(41.9)$ & $102(39.7)$ \\
\hline Female & $593(59.3)$ & $271(60.6)$ & $171(57.8)$ & $151(58.8)$ \\
\hline Intersex & $6(0.6)$ & $1(0.2)$ & $1(0.3)$ & $4(1.6)$ \\
\hline \multicolumn{5}{|l|}{ Ethnicity, n (\%) } \\
\hline White & $904(90.4)$ & 409 (91.5) & $259(87.5)$ & $236(91.8)$ \\
\hline Indian/Pakistani & $36(3.6)$ & $12(2.7)$ & $16(5.4)$ & $8(3.1)$ \\
\hline Mixed/Multiple ethnic groups & $16(1.6)$ & $6(1.3)$ & $8(2.7)$ & $2(0.8)$ \\
\hline Chinese/Japanese/Other East Asian & $8(0.8)$ & $3(0.7)$ & $4(1.4)$ & $1(0.4)$ \\
\hline Black/African/Caribbean & $21(2.1)$ & $10(2.2)$ & $5(1.7)$ & $6(2.3)$ \\
\hline Unknown & $15(1.5)$ & $7(1.6)$ & $4(1.4)$ & $4(1.6)$ \\
\hline \multicolumn{5}{|l|}{ Employment, n (\%) } \\
\hline Full-time employment & $315(31.5)$ & $171(38.3)$ & $88(29.7)$ & $56(21.8)$ \\
\hline Part-time employment & $135(13.5)$ & $61(13.6)$ & $37(12.5)$ & $37(14.4)$ \\
\hline Retired & $480(48.0)$ & $179(40.0)$ & $154(52.0)$ & $147(57.2)$ \\
\hline Student & $7(0.7)$ & $3(7.4)$ & $2(0.7)$ & $2(0.8)$ \\
\hline Unemployment & $63(6.3)$ & $33(0.7)$ & $15(5.1)$ & $15(5.8)$ \\
\hline \multicolumn{5}{|l|}{ Comorbidities, n (\%) } \\
\hline Hypertension & $397(39.7)$ & $184(41.2)$ & $109(36.8)$ & $104(40.5)$ \\
\hline High cholesterol & $350(35.0)$ & $149(33.3)$ & $105(35.5)$ & $96(37.4)$ \\
\hline \multicolumn{5}{|l|}{ Medications in current use, $n(\%)$} \\
\hline Insulin & $157(15.7)$ & $102(22.8)$ & $35(11.8)$ & $20(7.8)$ \\
\hline Metformin & $596(59.6)$ & $301(67.3)$ & $165(55.7)$ & $130(50.6)$ \\
\hline Other & $452(45.2)$ & $305(68.2)$ & $90(30.4)$ & 57 (22.2) \\
\hline
\end{tabular}

${ }^{\mathrm{a}}$ Elevated: baseline $\mathrm{HbA}_{1 \mathrm{c}} \geq 7.5 \%$; slightly elevated: baseline $\mathrm{HbA}_{1 \mathrm{c}} 6.5 \%-7.4 \%$; normal: baseline $\mathrm{HbA}_{1 \mathrm{c}}<6.5 \%$.

\section{Changes in Glycemic Control}

Considering all participants pooled across baseline $\mathrm{HbA}_{1 \mathrm{c}}$, those who completed the Low-Carb Program showed a statistically significant change in $\mathrm{HbA}_{1 \mathrm{c}}$ of $-1.17 \%$ (SD 1.43; $t_{527}=18.724$, $P<.001)$. Partial completers showed a statistically significant change in $\mathrm{HbA}_{1 \mathrm{c}}$ of $-0.6 \%$ (SD 1.69; $t_{143}=4.276, P<.001$ ) and 
noncompleters showed a nonsignificant $\mathrm{HbA}_{1 \mathrm{c}}$ change of only $-0.16 \%$ (SD 1.13; $t_{328}=2.54, P=.01$ ). Results stratified by baseline $\mathrm{HbA}_{1 \mathrm{c}}$ are presented in Table 3, and results for just Low-Carb Program completers are presented in Figure 2.

\section{Body Weight}

Considering all baseline $\mathrm{HbA}_{1 \mathrm{c}}$ groups combined, Low-Carb Program completers $(n=528)$ showed a significant reduction in weight, with a mean body weight change of $-7.45 \mathrm{~kg}$ (SD 12.63) or $-7.0 \%$ (SD 12.81\%; $\left.t_{527}=13.551, P<.001\right)$. Partial completers $(\mathrm{n}=144)$ showed a reduction in weight, with a mean body weight change of $-2.13 \mathrm{~kg}$ (SD 16.40) or -1.1\% (SD 25.42\%); however, this weight change was not statistically significant $\left(t_{143}=1.563\right.$, $P=.12)$. Noncompleters $(\mathrm{n}=328)$ did not have a statistically significant change in weight, with mean change of $-0.35 \mathrm{~kg}$ (SD 10.13) or $0.7 \%$ (SD 13.41\%; $t_{327}=0.625, P=.53$ ). Results, stratified by baseline $\mathrm{HbA}_{1 \mathrm{c}}$, are presented in Table 4 , and results for just Low-Carb Program completers are presented in Figure 3.

\section{Hypoglycemic Medications}

The majority of participants $(714 / 1000,71.40 \%)$ were prescribed at least one hypoglycemic medication at baseline. At 1 year, of those originally prescribed medications, 289/714 (40.4\%) individuals were able to stop one or more hypoglycemic medications. Of the 743 participants who started with an $\mathrm{HbA}_{1 \mathrm{c}}$, equal to or above the type 2 diabetes threshold of $6.5 \%, 195$ $(26.2 \%)$ reduced their $\mathrm{HbA}_{1 \mathrm{c}}$ to below the threshold while taking no glucose-lowering medications or just metformin.

For participants who completed the program, the proportion prescribed hypoglycemic medications changed significantly between baseline and follow-up for metformin $\left(\chi_{24}^{2}=146.5\right.$, $P<.05$ ) and other hypoglycemic medications (all hypoglycemic medications other than metformin and insulin: $\chi_{24}^{2}=73.8$, $P<.05)$. However, there was no significant change in being prescribed insulin $\left(\chi_{24}^{2}=34.1, P=.08\right.$; see Figure 4$)$.

Table 3. Change in $\mathrm{HbA}_{1 \mathrm{c}}$ from baseline to 1-year follow-up by intervention completion.

\begin{tabular}{|c|c|c|c|c|}
\hline Baseline $\mathrm{HbA}_{1 \mathrm{c}}$ group & Baseline $\mathrm{HbA}_{1 \mathrm{c}}(\%)$, mean $(\mathrm{SD})$ & 1-year $\mathrm{HbA}_{1 \mathrm{c}}(\%)$ mean $(\mathrm{SD})$ & $\mathrm{HbA}_{1 \mathrm{c}}$ change $(\%)$, mean $(\mathrm{SD})$ & $P$ value \\
\hline \multicolumn{5}{|l|}{ Pooled (all participants) } \\
\hline All participants $(\mathrm{N}=1000)$ & $7.78(2.10)$ & $7.03(2.04)$ & $-0.76(1.46)$ & $<.001$ \\
\hline Completers $(\mathrm{N}=528)$ & $7.40(1.81)$ & $6.23(1.19)$ & $-1.17(1.43)$ & $<.001$ \\
\hline Partial completers $(\mathrm{N}=144)$ & $7.00(1.72)$ & $6.40(1.44)$ & $-0.60(1.69)$ & $<.001$ \\
\hline Noncompleters $(\mathrm{N}=328)$ & $8.75(2.33)$ & $8.59(2.43)$ & $-0.16(1.13)$ & .01 \\
\hline \multicolumn{5}{|l|}{ Elevated $\left(\mathrm{HbA}_{1 \mathrm{c}} \geq 7.5 \%\right)$} \\
\hline All participants $(\mathrm{n}=447)$ & $9.58(1.80)$ & $8.36(2.22)$ & $-1.22(1.75)$ & $<.001$ \\
\hline Completers $(\mathrm{N}=191)$ & $9.23(1.71)$ & $7.06(1.35)$ & $-2.16(1.76)$ & $<.001$ \\
\hline Partial completers $(\mathrm{N}=47)$ & $8.88(1.37)$ & $7.26(1.67)$ & $-1.62(1.97)$ & $<.001$ \\
\hline Noncompleters (N=209) & $10.06(1.84)$ & $9.79(2.12)$ & $-0.28(1.06)$ & $<.001$ \\
\hline \multicolumn{5}{|c|}{ Slightly elevated $\left(\mathrm{HbA}_{1 \mathrm{c}} 6.5-7.4 \%\right)$} \\
\hline All participants $(\mathrm{N}=296)$ & $6.90(0.28)$ & $6.22(0.90)$ & $-0.68(0.89)$ & $<.001$ \\
\hline Completers $(\mathrm{N}=182)$ & $6.88(0.27)$ & $6.01(0.69)$ & $-0.87(0.68)$ & $<.001$ \\
\hline Partial completers $(\mathrm{N}=42)$ & $6.92(0.31)$ & $6.23(0.86)$ & $-0.69(0.87)$ & $<.001$ \\
\hline Noncompleters (N=72) & $6.93(0.27)$ & $6.74(1.18)$ & $-0.19(1.16)$ & .16 \\
\hline \multicolumn{5}{|l|}{ Normal $\left(\mathrm{HbA}_{1 \mathrm{c}}<6.5 \%\right)$} \\
\hline All participants $(\mathrm{N}=257)$ & $5.68(0.68)$ & $5.65(0.95)$ & $-0.03(1.06)$ & .64 \\
\hline Completers $(\mathrm{N}=155)$ & $5.77(0.61)$ & $5.47(0.75)$ & $-0.30(0.75)$ & $<.001$ \\
\hline Partial completers $(\mathrm{N}=55)$ & $5.45(0.80)$ & $5.79(1.22)$ & $0.33(1.36)$ & .07 \\
\hline Noncompleters $(\mathrm{N}=47)$ & $5.66(0.69)$ & $6.08(1.07)$ & $0.42(1.24)$ & .02 \\
\hline
\end{tabular}


Figure 2. Mean glycated hemoglobin $\mathrm{A}_{1 \mathrm{c}}\left(\mathrm{HbA}_{1 \mathrm{c}}\right)$ levels at baseline and 1-year follow-up for participants who completed the program (engaged with all 10 weekly Low Carb Program modules). Error bars represent the SD; * represents significant difference from baseline.

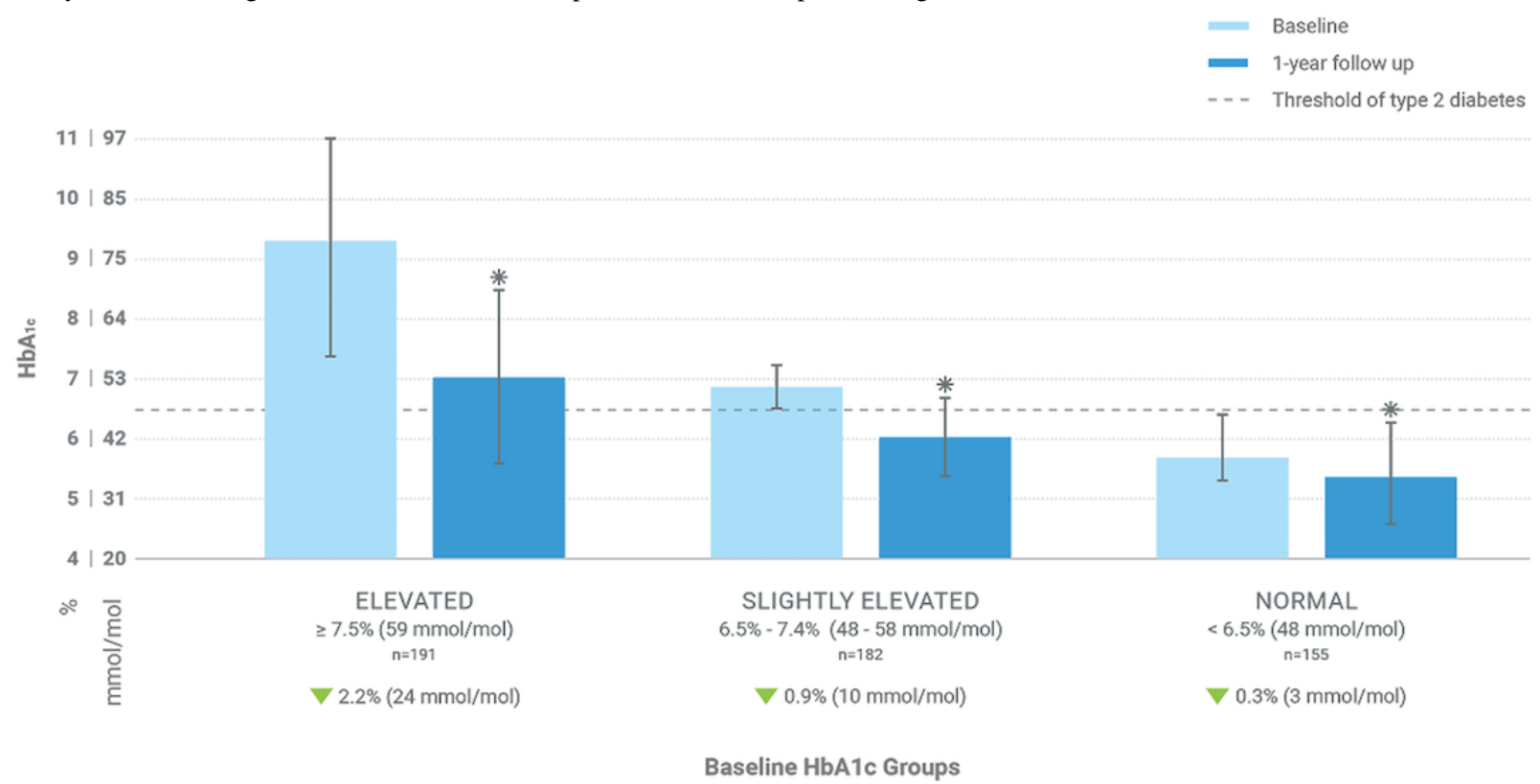

Table 4. Change in participant body weight from baseline to 1-year follow-up for people with elevated or slightly elevated baseline $\mathrm{Hb}_{1 \mathrm{c}}$ by intervention completion amount.

\begin{tabular}{|c|c|c|c|c|c|}
\hline Baseline $\mathrm{HbA}_{1 \mathrm{c}}$ group & $\begin{array}{l}\text { Baseline weight }(\mathrm{kg}) \text {, } \\
\text { mean }(\mathrm{SD})\end{array}$ & $\begin{array}{l}\text { 1-year weight }(\mathrm{kg}) \text {, } \\
\text { mean }(\mathrm{SD})\end{array}$ & $\begin{array}{l}\text { 1-year percent weight change, } \\
\text { mean }(\mathrm{SD})\end{array}$ & $\begin{array}{l}\text { 1-year weight change }(\mathrm{kg}) \text {, } \\
\text { mean }(\mathrm{SD})\end{array}$ & $P$ value \\
\hline \multicolumn{6}{|l|}{ Pooled (all participants) } \\
\hline All participants $(\mathrm{N}=1000)$ & $89.63(23.13)$ & $85.28(20.73)$ & $-3.31(15.93)$ & $-4.35(12.93)$ & $<.001$ \\
\hline Completers $(\mathrm{n}=528)$ & $88.88(22.16)$ & $81.43(17.98)$ & $-6.97(12.83)$ & $-7.45(12.63)$ & $<.001$ \\
\hline Partial completers $(n=144)$ & $87.77(22.91)$ & $85.64(19.02)$ & $1.09(25.51)$ & $-2.13(16.39)$ & .12 \\
\hline Noncompleters $(\mathrm{n}=328)$ & $91.66(24.63)$ & $91.31(23.93)$ & $0.65(13.41)$ & $-0.35(10.13)$ & .53 \\
\hline \multicolumn{6}{|l|}{ Elevated $\left(\mathrm{HbA}_{1 \mathrm{c}} \geq 7.5 \%\right)$} \\
\hline All participants $(\mathrm{N}=447)$ & $92.88(23.96)$ & $89.46(22.24)$ & $-2.39(14.70)$ & $-3.42(12.32)$ & $<.001$ \\
\hline Completers (n=191) & $92.98(23.62)$ & $84.96(18.85)$ & $-6.94(13.90)$ & $-8.01(13.83)$ & $<.001$ \\
\hline Partial completers $(n=47)$ & $90.49(20.17)$ & $89.76(19.60)$ & $0.98(19.88)$ & $-0.72(13.77)$ & .72 \\
\hline Noncompleters (n=209) & $93.33(25.09)$ & $93.49(24.83)$ & $1.00(12.89)$ & $0.16(8.64)$ & .79 \\
\hline \multicolumn{6}{|c|}{ Slightly elevated $\left(6.5<\mathrm{HbA}_{1 \mathrm{c}}<7.4 \%\right)$} \\
\hline All participants $(\mathrm{N}=296)$ & $88.16(22.36)$ & $82.44(19.37)$ & $-5.14(13.83)$ & $-5.72(12.61)$ & $<.001$ \\
\hline Completers (n=182) & $87.94(20.60)$ & $80.64(16.87)$ & $-7.27(10.78)$ & $-7.30(11.34)$ & $<.001$ \\
\hline Partial completers $(n=42)$ & $87.37(24.09)$ & $80.83(18.78)$ & $-4.66(20.47)$ & $-6.54(15.17)$ & .008 \\
\hline Noncompleters (n=72) & $89.17(25.67)$ & $87.94(24.27)$ & $0.02(14.79)$ & $-1.23(13.15)$ & .43 \\
\hline \multicolumn{6}{|l|}{ Normal $\left(\mathrm{HbA}_{1 \mathrm{c}}<6.5 \%\right)$} \\
\hline All participants ( $\mathrm{N}=257)$ & 85.67 (21.79) & $81.27(18.06)$ & $-2.79(19.70)$ & $-4.41(14.19)$ & $<.001$ \\
\hline Completers (n=155) & $84.93(21.34)$ & $78.00(17.46)$ & $-6.65(13.70)$ & $-6.93(12.56)$ & $<.001$ \\
\hline Partial completers $(n=55)$ & $85.76(24.33)$ & $85.79(18.19)$ & $5.58(31.97)$ & $0.03(18.80)$ & .99 \\
\hline Noncompleters $(\mathrm{n}=47)$ & $88.04(20.38)$ & $86.77(17.74)$ & $0.14(13.74)$ & $-1.27(11.02)$ & .43 \\
\hline
\end{tabular}


Figure 3. Mean weight at baseline and 1-year follow-up for participants who completed the program (engaged with all 10 weekly Low Carb Program modules). Error bars represent the SD; * represents significant difference from baseline.

Baseline

1-year follow up

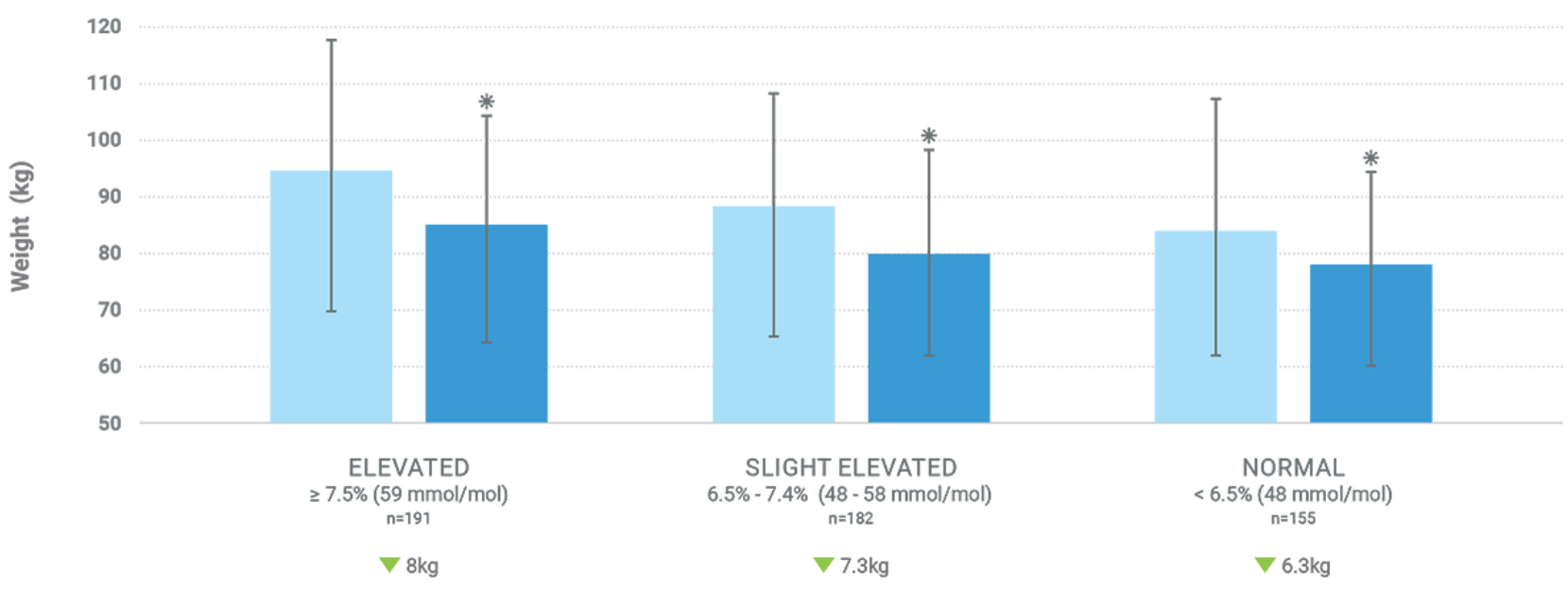

Baseline HbA1c Groups

Figure 4. Frequency of change in the number of medications taken for all completers. Bars represent total users of each drug type with the type of change (increase, no change, or elimination) stacked within the bar and the relative frequency noted next to each section. The total number of users of each medication type is noted at the top of each bar.

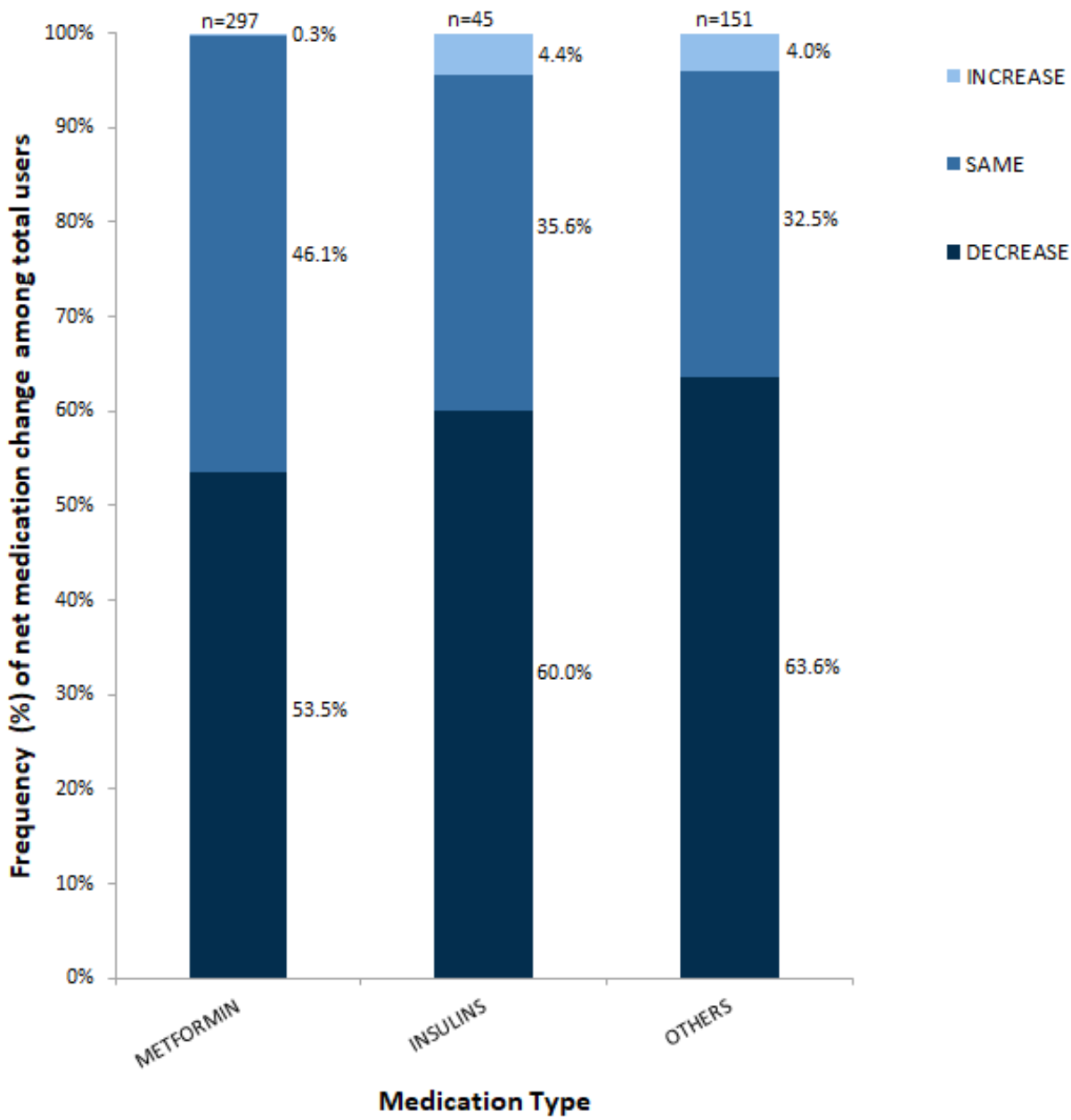




\section{Discussion}

The Low-Carb Program is a digitally delivered, peer-supported, nutrition-focused, structured 10-week health intervention aimed at improving glycemic control, reducing hypoglycemic medication use, and promoting weight loss among adults with type 2 diabetes. This was not a randomized controlled trial, so we cannot compare the 12-month results to a control or standard-of-care group; therefore, the results of our trial should be interpreted cautiously because the study used convenience sampling, open-label, single-arm design, pre-post self-reported outcomes, and $71 \%$ of participants reported outcomes at 12 months. Even so, when adults with type 2 diabetes participate in the Low-Carb Program, and especially when they finish all 10 modules of the program, they report significantly reduced $\mathrm{HbA}_{1 \mathrm{c}}$, weight loss, and reduced medications. The percentage of individuals with an $\mathrm{HbA}_{1 \mathrm{c}}$ level less than $6.5 \%$ (indicating good diabetes control) increased from $25.70 \%$ (257/1000) to $50.30 \%$ (503/1000). Furthermore, $46.00 \%$ (464/1000) of participants lost at least $5 \%$ of their body weight. Also, of participants who were taking at least one hypoglycemic diabetes medication at baseline, $289 / 714(40.5 \%)$ reduced one or more of these medications.

The percentage of individuals with an $\mathrm{HbA}_{1 \mathrm{c}}$ level of less than $6.5 \%$ increased from $25.70 \%$ (257/1000) to $50.30 \%$ (503/1000). This degree of control, when achieved through pharmacotherapy, is often accompanied by weight gain and risk for hypoglycemic events [27]. Indeed, as the now famous Action to Control Cardiovascular Risk in Diabetes (ACCORD) study reported, intensive hypoglycemic medical therapy "increased mortality and did not significantly reduce major cardiovascular events" [28].

As in other studies using a carbohydrate-restricted dietary approach, including Dr Unwin's in-person program on which the Low-Carb Program was partially modeled [14,17,29], we achieved $\mathrm{HbA}_{1 \mathrm{c}}$ reduction with weight loss and decreased hypoglycemic medication use. This approach is given further credence by a recent meta-analysis, which concluded that carbohydrate-reduced interventions improve glucose control, in addition to other positive health effects such as improved triglyceride and high-density lipoprotein cholesterol [30].

Our study has several limitations. Although we encouraged participants to eat a carbohydrate-restricted diet, we did not measure their dietary intake. We also measured health outcomes (weight, glycemic control, and medication changes) using self-report, rather than measuring them directly or through medical records. However, previous research has found that these self-reported health outcomes can be quite close to actual values [31,32]. Another limitation was our rate of delivering the entire intervention, as only $528(52.8 \%)$ completed all modules. However, a high rate $(70.8 \%)$ reported 12 -month outcomes. On the other hand, given that this program was entirely automated and had a wide reach, a large number of individuals were able to complete the program.

For participants who fully engage, an automated online program teaching a carbohydrate-reduced diet to adults with type 2 diabetes may facilitate glycemic control, weight loss, and reduced need for hypoglycemic medication. Although our design does not support causal conclusions, the program may be a useful adjunct for lifestyle self-management for adults with type 2 diabetes.

\section{Acknowledgments}

We thank the Diabetes.co.uk forum community who have been discussing low-carb diets for over a decade and the community on the Low-Carb Program who have been helping one another on their own low-carb journeys. Thank you to Dr Jen Unwin and also to Harkrishan Panesar for his help in data analysis. LRS was supported by funding from the NIH, a K01 from the National Institute of Diabetes and Digestive and Kidney Diseases (DK107456). The funder had no role in study design, data collection and analysis, decision to publish, or preparation of the manuscript.

\section{Conflicts of Interest}

CS is employed by Diabetes.co.uk, which runs the Low-Carb Program. The rest of the authors declare no conflicts of interest.

\section{References}

1. Stratton IM, Adler AI, Neil HA, Matthews DR, Manley SE, Cull CA, et al. Association of glycaemia with macrovascular and microvascular complications of type 2 diabetes (UKPDS 35): prospective observational study. BMJ 2000 Aug 12;321(7258):405-412 [FREE Full text] [Medline: 10938048]

2. World Health Organization. 2016. Global report on diabetes URL: http://www.who.int/diabetes/global-report/en/ [accessed 2018-04-15] [WebCite Cache ID 6yhoQgIgp]

3. Dieleman JL, Baral R, Birger M, Bui AL, Bulchis A, Chapin A, et al. US spending on personal health care and public health, 1996-2013. JAMA 2016 Dec 27;316(24):2627-2646 [FREE Full text] [doi: 10.1001/jama.2016.16885] [Medline: 28027366]

4. Seuring T, Archangelidi O, Suhrcke M. The economic costs of type 2 diabetes: a global systematic review. Pharmacoeconomics 2015 Aug;33(8):811-831 [FREE Full text] [doi: 10.1007/s40273-015-0268-9] [Medline: 25787932]

5. Karter AJ, Nundy S, Parker MM, Moffet HH, Huang ES. Incidence of remission in adults with type 2 diabetes: the diabetes \& aging study. Diabetes Care 2014 Dec;37(12):3188-3195 [FREE Full text] [doi: 10.2337/dc14-0874] [Medline: 25231895] 
6. Feinman RD, Pogozelski WK, Astrup A, Bernstein RK, Fine EJ, Westman EC, et al. Dietary carbohydrate restriction as the first approach in diabetes management: critical review and evidence base. Nutrition 2015 Jan;31(1):1-13 [FREE Full text] [doi: 10.1016/j.nut.2014.06.011] [Medline: 25287761]

7. Hussain TA, Mathew TC, Dashti AA, Asfar S, Al-Zaid N, Dashti HM. Effect of low-calorie versus low-carbohydrate ketogenic diet in type 2 diabetes. Nutrition 2012 Oct;28(10):1016-1021. [doi: 10.1016/j.nut.2012.01.016] [Medline: 22673594]

8. Nielsen JV, Joensson EA. Low-carbohydrate diet in type 2 diabetes: stable improvement of bodyweight and glycemic control during 44 months follow-up. Nutr Metab (Lond) 2008 May 22;5(1):14 [FREE Full text] [doi: 10.1186/1743-7075-5-14] [Medline: 18495047$]$

9. Yancy W, Foy M, Chalecki A, Vernon M, Westman E. A low-carbohydrate, ketogenic diet to treat type 2 diabetes. Nutr Metab (Lond) 2005 Dec 01;2(1):34 [FREE Full text] [doi: 10.1186/1743-7075-2-34] [Medline: 16318637]

10. Garg A, Bantle JP, Henry RR, Coulston AM, Griver KA, Raatz SK, et al. Effects of varying carbohydrate content of diet in patients with non-insulin-dependent diabetes mellitus. JAMA 1994 May 11;271(18):1421-1428. [Medline: 7848401]

11. Reaven GM. Effect of dietary carbohydrate on the metabolism of patients with non-insulin dependent diabetes mellitus. Nutr Rev 1986 Feb;44(2):65-73. [Medline: $\underline{\text { 3703391] }}$

12. Bian R, Piatt G, Sen A, Plegue MA, De MM, Hafez D, et al. The effect of technology-mediated diabetes prevention interventions on weight: a meta-analysis. J Med Internet Res 2017 Mar 27;19(3):e76 [FREE Full text] [doi: 10.2196/jmir.4709] [Medline: 28347972]

13. Saslow L, Mason A, Kim S, Goldman V, Ploutz-Snyder R, Bayandorian H, et al. An online intervention comparing a very low-carbohydrate ketogenic diet and lifestyle recommendations versus a plate method diet in overweight individuals with type 2 diabetes: a randomized controlled trial. J Med Internet Res 2017 Feb 13;19(2):e36 [FREE Full text] [doi: 10.2196/jmir.5806] [Medline: 28193599]

14. McKenzie A, Hallberg S, Creighton B, Volk B, Link T, Abner M, et al. novel intervention including individualized nutritional recommendations reduces hemoglobin a1c level, medication use, and weight in type 2 diabetes. JMIR Diabetes 2017 Mar 07;2(1):e5. [doi: 10.2196/diabetes.6981]

15. Thomas J, Leahey T, Wing R. An automated internet behavioral weight-loss program by physician referral: a randomized controlled trial. Diabetes Care 2015 Jan;38(1):9-15 [FREE Full text] [doi: 10.2337/dc14-1474] [Medline: 25404659]

16. Ross KM, Wing RR. Implementation of an internet weight loss program in a worksite setting. J Obes 2016;2016:9372515 [FREE Full text] [doi: 10.1155/2016/9372515] [Medline: 26942006]

17. Unwin D, Cuthbertson D, Feinman R, Sprung V. A pilot study to explore the role of a low-carbohydrate intervention to improve GGT levels and HbA1c. Diabesity in Practice 2015;4:102-108 [FREE Full text]

18. Foster-Powell K, Holt S, Brand-Miller J. International table of glycemic index and glycemic load values: 2002. Am J Clin Nutr 2002 Jul;76(1):5-56. [doi: $\underline{10.1093 / a j c n / 76.1 .5}$ ] [Medline: $\underline{12081815]}$

19. National Institute for Health and Care Excellence. Type 2 Diabetes in Adults: Management. London: National Institute for Health and Care Excellence (UK); 2015.

20. Burgess E, Hassmén P, Welvaert M, Pumpa K. Behavioural treatment strategies improve adherence to lifestyle intervention programmes in adults with obesity: a systematic review and meta-analysis. Clin Obes 2017 Apr;7(2):105-114. [doi: 10.1111/cob.12180] [Medline: 28199047]

21. Carver C, Scheier M. Control theory: a useful conceptual framework for personality-social, clinical, and health psychology. Psychol Bull 1982 Jul;92(1):111-135. [Medline: 7134324]

22. Harkin B, Webb TL, Chang BP, Prestwich A, Conner M, Kellar I, et al. Does monitoring goal progress promote goal attainment? A meta-analysis of the experimental evidence. Psychol Bull 2016 Feb;142(2):198-229. [doi: $\underline{10.1037 / b u l 0000025]}$ [Medline: 26479070]

23. Fisher EB, Boothroyd RI, Elstad EA, Hays L, Henes A, Maslow GR, et al. Peer support of complex health behaviors in prevention and disease management with special reference to diabetes: systematic reviews. Clin Diabetes Endocrinol 2017;3:4 [FREE Full text] [doi: 10.1186/s40842-017-0042-3] [Medline: 28702258]

24. Sylvetsky AC, Nandagopal R, Nguyen TT, Abegg MR, Nagarur M, Kaplowitz P, et al. Buddy Study: partners for better health in adolescents with type 2 diabetes. World J Diabetes 2015 Dec 25;6(18):1355-1362 [FREE Full text] [doi: 10.4239/wjd.v6.i18.1355] [Medline: 26722619]

25. Leahey TM, Wing RR. A randomized controlled pilot study testing three types of health coaches for obesity treatment: Professional, peer, and mentor. Obesity (Silver Spring) 2013 May;21(5):928-934 [FREE Full text] [doi: 10.1002/oby.20271] [Medline: 23784896]

26. Hwang KO, Ottenbacher AJ, Green AP, Cannon-Diehl MR, Richardson O, Bernstam EV, et al. Social support in an Internet weight loss community. Int J Med Inform 2010 Jan;79(1):5-13 [FREE Full text] [doi: 10.1016/j.ijmedinf.2009.10.003] [Medline: 19945338]

27. Heller S. Weight gain during insulin therapy in patients with type 2 diabetes mellitus. Diabetes Res Clin Pract 2004 Sep;65 Suppl 1:S23-S27. [doi: 10.1016/j.diabres.2004.07.005] [Medline: 15315867] 
28. Action to Control Cardiovascular Risk in Diabetes Study Group, Gerstein HC, Miller ME, Byington RP, Goff DC, Bigger JT, et al. Effects of intensive glucose lowering in type 2 diabetes. N Engl J Med 2008 Jun 12;358(24):2545-2559 [FREE Full text] [doi: 10.1056/NEJMoa0802743] [Medline: 18539917]

29. Saslow LR, Kim S, Daubenmier JJ, Moskowitz JT, Phinney SD, Goldman V, et al. A randomized pilot trial of a moderate carbohydrate diet compared to a very low carbohydrate diet in overweight or obese individuals with type 2 diabetes mellitus or prediabetes. PLoS One 2014;9(4):e91027 [FREE Full text] [doi: 10.1371/journal.pone.0091027] [Medline: 24717684]

30. Meng Y, Bai H, Wang S, Li Z, Wang Q, Chen L. Efficacy of low carbohydrate diet for type 2 diabetes mellitus management: a systematic review and meta-analysis of randomized controlled trials. Diabetes Res Clin Pract 2017 Sep;131:124-131. [doi: 10.1016/j.diabres.2017.07.006] [Medline: 28750216]

31. McAdams MA, Van Dam RM, Hu FB. Comparison of self-reported and measured BMI as correlates of disease markers in US adults. Obesity (Silver Spring) 2007 Jan;15(1):188-196 [FREE Full text] [doi: 10.1038/oby.2007.504] [Medline: 17228047]

32. Løvaas KF, Cooper J, Sandberg S, Røraas T, Thue G. Feasibility of using self-reported patient data in a national diabetes register. BMC Health Serv Res 2015 Dec 15;15(1):553 [FREE Full text] [doi: 10.1186/s12913-015-1226-0] [Medline: 26666413]

\section{Abbreviations \\ $\mathbf{H b A}_{1 \mathbf{c}}$ : glycated hemoglobin $\mathrm{A}_{1 \mathrm{c}}$ \\ IRB: Institutional Review Board}

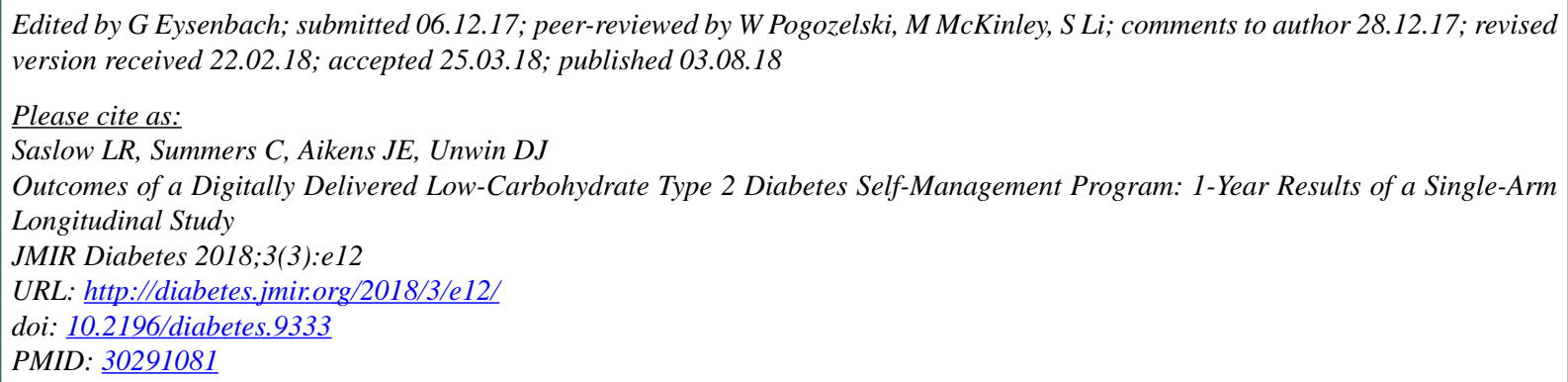

CLaura R Saslow, Charlotte Summers, James E Aikens, David J Unwin. Originally published in JMIR Diabetes (http://diabetes.jmir.org), 03.08.2018. This is an open-access article distributed under the terms of the Creative Commons Attribution License (https://creativecommons.org/licenses/by/4.0/), which permits unrestricted use, distribution, and reproduction in any medium, provided the original work, first published in JMIR Diabetes, is properly cited. The complete bibliographic information, a link to the original publication on http://diabetes.jmir.org/, as well as this copyright and license information must be included. 